\title{
Test yourself: inability to squat
}

\author{
Hatice Tuba Sanal ${ }^{1}$
}

QUESTION-Male patient in his twenties, referred to MRI with an asymmetry in his right buttock and difficulty in squatting (Figs 1, 2, 3, and 4).
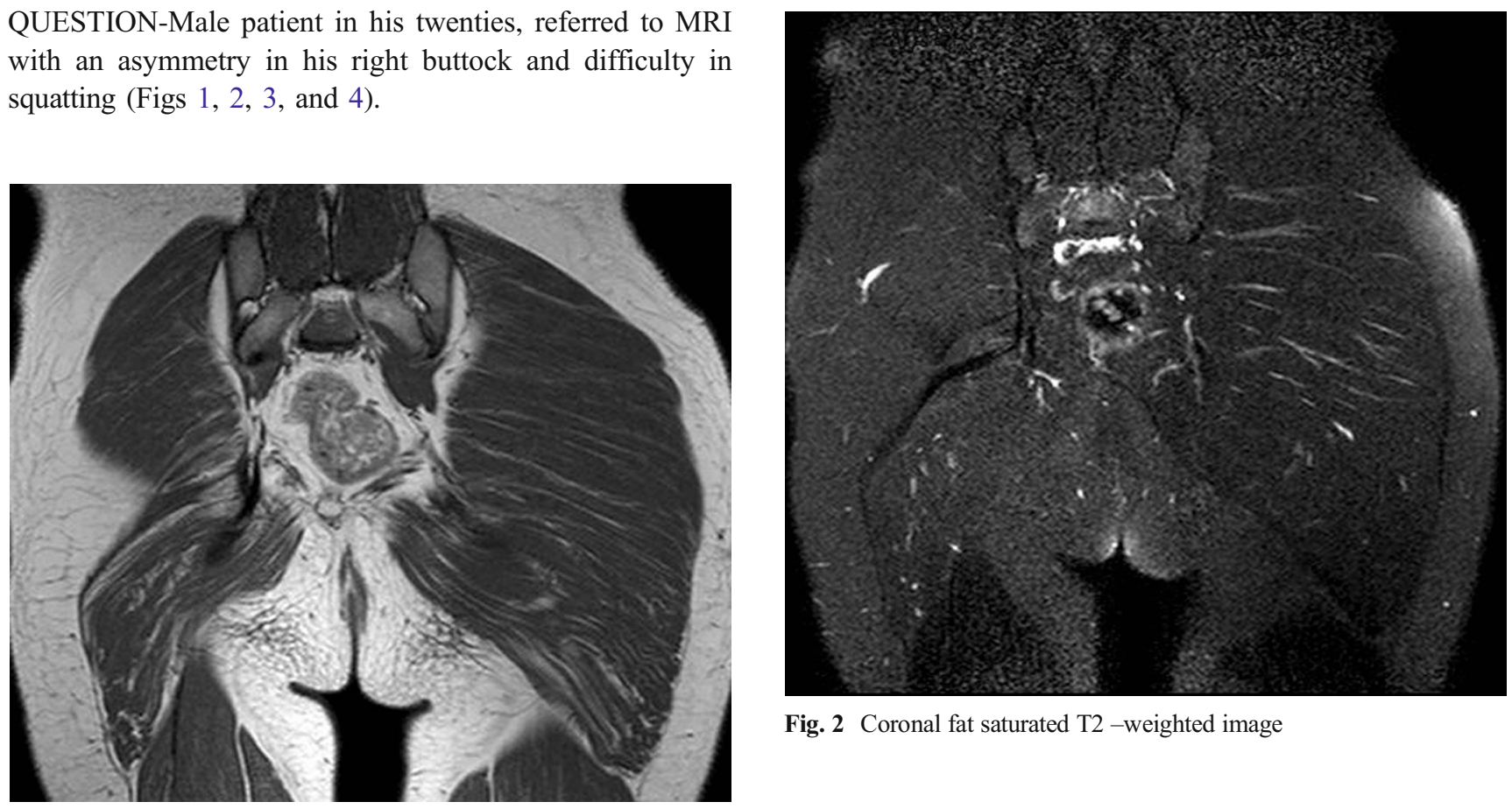

Fig. 2 Coronal fat saturated T2 -weighted image

Fig. 1 Coronal T1-weighted image

The diagnosis can be found at doi: 10.1007/s00256-016-2519-Z

$\bowtie$ Hatice Tuba Sanal

tubasanal@gmail.com

1 Department of Radiology, Gulhane School of Medicine, Health Sciences University, Gn.Tevfik Saglam Cad., 06018 Kecioren, Ankara, Turkey 
Fig. 3 Axial T1-weighted image

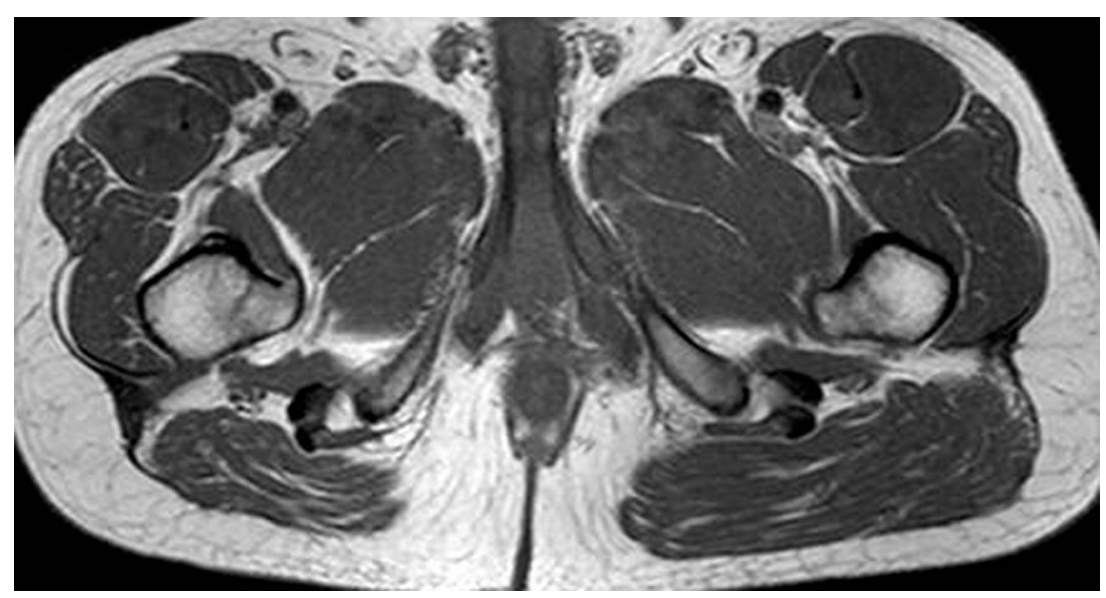

Fig. 4 Axial T1-weighted image

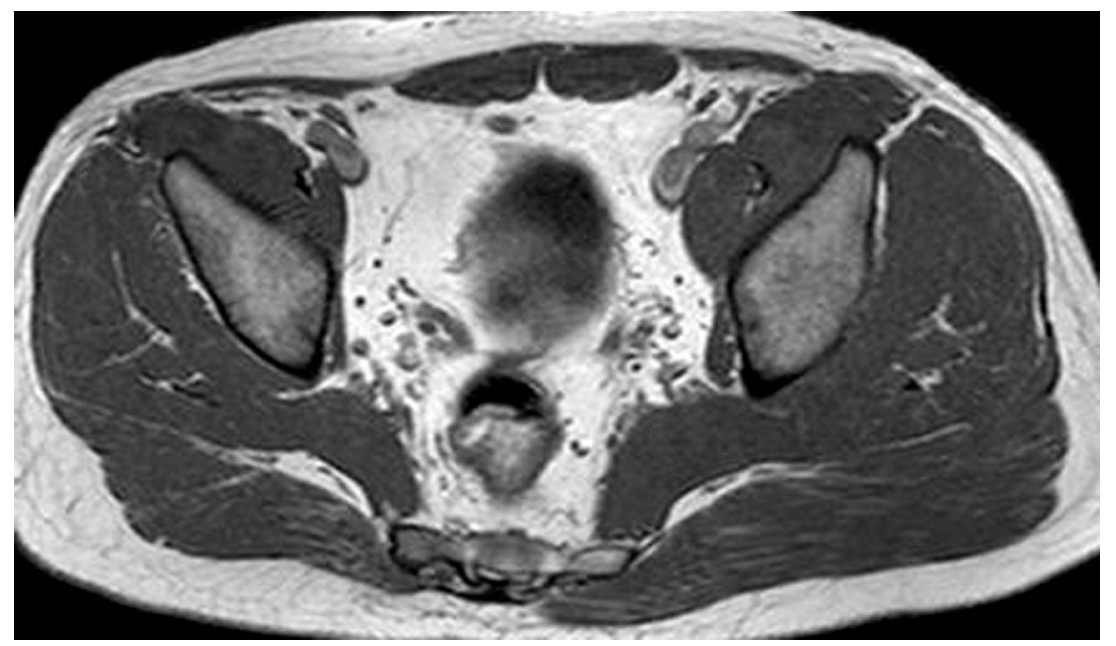

